Kelaniya Journal of Human Resource Management

Volume 12, Number 01 - January 2017

DOI: http://doi.org/10.4038/kjhrm.v12i1.42

\title{
The Impact of Work Life Balance on Employee Performance with Reference to Telecommunication Industry in Sri Lanka: A Mediation Model
}

\author{
M. D. V. S. Mendis ${ }^{1}$ and W. A. S. Weerakkody ${ }^{2}$ \\ ${ }^{1}$ Dialog Axiata PLC, Sri Lanka Telecom \\ ${ }^{2}$ Department of Human Resource Management, Faculty of Commerce and \\ Management Studies, University of Kelaniya, Sri Lanka \\ ${ }^{1}$ virajisachinthamendis@gmail.com, ${ }^{2}$ was@kln.ac.lk \\ (iD) https://orcid.org/0000-0003-3710-8528
}

\begin{abstract}
In today's dynamic business environment, work life balance has become one of the key issues faced by many employees all over the world. Maintaining work life balance is an issue increasingly recognized as of strategic importance to organization and of significance to employees.

A lack of work life balance also has an adverse effect on their employer's prospects for success in many respects. The main objective of this study is to carry out research on the Sri Lankan telecommunication industry and recognize the impact of work life balance on the employee performance. And also to identify whether the work life balance leads to higher employee performance through employee job satisfaction. The target population of this research is executive level married employees in telecommunication industry in Sri Lanka. This investigation area is used Cluster sampling method to select 2 major companies in telecommunication industry (i.e., Dialog Axiata PLC and Sri Lanka Telecom-Sample Size 100). Data were gathered through questionnaire method. In this study, for the purpose of hypothesis testing the researcher used univariate, bivariate and multivariate statistics methods. The Data were analyzed through SPSS 15.0 software to find out the relationship between variables. Findings of the study reveal that there is a strong relationship between work life balance and employee performance, a strong relationship between work life balance and employee job satisfaction and a strong relationship between employee job satisfaction and employee performance. All these relationships are positive and have significant levels. The research findings give evidence that the better work life balance of the employees leads to increased employee performance and employee job satisfaction.
\end{abstract}

Keywords: Work Life Balance, Employee Performance, Employee Job Satisfaction, Telecommunication Industry 


\section{Introduction}

In today's ever demanding work environment lot of people face the problem of balancing work and family life. Despite the worldwide quest for work life balance here on referred to as work life balance (WLB), very few have found an acceptable definition and concept. WLB does not mean an equal balance; it is about adjusting the working patterns to allow employees to combine work with their other responsibilities such as caring for children or elderly relatives. WLB is a combination of interactions among different areas of one's life, the advantages and disadvantages associated with that balance or imbalance can affect multiple levels of society. The disadvantages associated with WLB can impact both employee and employer. For the employee, consequences can have a negative impact on work and life satisfaction, mental health, physical health and on individual performance in organization (Guest, 2001). For employers, the consequences of poor work life balance will be poor performance, absenteeism, sick leave and higher staff turnover, recruitment and training costs (Department of Trade and Industry, 2001).

In simply WLB means the amount of time you spend doing your job compared with the amount of time you spend with your family and doing things you enjoy.

An organization needs to magnetize and preserve valued employees in highly competitive labor market. It is a strong motivating factor for increased organizational awareness and action with regard to implementation and management of work life balance strategies. WLB is an important area of human resource management that is receiving increasing attention from government, researchers, management, and employee representatives and popular media.

WLB, from the employee perspective, is the maintenance of a balance between responsibilities at work and at home. Employers view the benefits or the working conditions that they provide to help employees balance the family and the work domains as work life benefits (Russell \& Bowman, 2000). Initially, the concept of work life conflict focused on the impact of family demands on work. It now extends to the impact work has on individual stress, relationships and family well-being (Russell \& Bowman, 2000). 
Work-to-family conflict occurs when experiences at work interfere with family life inflexible work hours, work overload, interpersonal conflict at work, unsupportive supervisor organization. Family-to-work conflict occurs when experiences in the family interfere with work life primary responsibility for children, elder care responsibilities, interpersonal conflict within the family unit, unsupportive family members.

This project intends to identify is there any relationship between work life balance and employee performance. And also introduce appropriate employment practices to help employees achieve a better work life balance which can provide tangible benefits to the organization as well as the individual. It can enable employees to feel more in control of their working life and lead to increased productivity, lower absenteeism and a happier, less stressed work force. This project also examines how to promote good WLB in the telecommunication industry of Sri Lanka and highlights some benefits for the organizations.

\section{Problem Statement}

There have been a number of valuable studies regarding work life balance and employee performance. In the Sri Lankan context there are less researches based on this topic. Therefore, there is a research gap on this regard. By conducting this research, the researcher hopes to fill the existing research gap. There is no substantive empirical study has been conducted to investigate, how work life balance influences employee performance in telecommunication industry in Sri Lanka. This is the research gap that will be primarily addressed in this research.

\section{Research Objectives}

The general objective of this study was to identify the relationship between work life balance and employee performance in telecommunication industry in Sri Lanka. The study attempted to achieve the following specific objectives.

i. To identify the relationship between work life balance and employee job satisfaction.

ii. To identify the relationship between employee job satisfaction and employee performance. 
iii. To identify the relationship between work life balance and employee performance.

iv. To identify the mediation effect between work life balance and employee performance.

\section{Literature Review}

The literature review is an evaluative report of information on the findings of the comprehensive study carried out, on the areas of work life balance and employee performance in telecommunication industry, gaining the knowledge required to carry out the advanced survey.

"Work Life Balance isn't only about families and childcare. Nor is it about working less. It's about working smart. About being fresh enough to give all you need to both work and home, without jeopardising one for the other. And it's a necessity for everyone, at whatever your stage in life" (Department of Trade and Industry, 2001). Reducing stress and absence through employer flexibility should not only result in a more satisfied and more productive work force, but also have a knock on effect on improved recruitment and retention" (Human Resource Management International Digest, 2004).

The achievement of better WLB can yield dividends for employers in terms of having a more motivated, productive, less stressed workforce, increased productivity, and reduced absenteeism. WLB can have impact on both individual as well as the organization. The independent variable of this research is work life balance and it can be divided in to two main areas as work centered life and family centered life. In simply, work centered life means that people give more priority to their work than their family. This will cause to occur work-to-family conflicts. Most probably work centered life occurs due to reasons such as inflexible work hours, interpersonal conflict at work, work overload, and unsupportive supervisor. Family centered life means that people give more priority to their families than their work. This causes to occur family-to-work conflicts. Most probably family centered life occurs due to reasons such as primary responsibility for children, elder care responsibilities, interpersonal conflict within the family unit and unsupportive family members (PsycINFO Database Record (c), 2010). 
Dependent variable of this research is employee performance. In any given situation, whether it is in sport or work, we can drill it down to a simple formula.$$
\mathbf{P}=\mathbf{P}-\mathbf{I}
$$ \\ Performance $=$ Potential - Interference}

Employee performance management is a process for establishing a shared workforce understanding about what is to be achieved at an organization level. It is about aligning the organizational objectives with the employees' agreed measures, skills, competency requirements, development plans and the delivery of results. The emphasis is on improvement, learning and development in order to achieve the overall business strategy and to create a high performance workforce. Performance evaluation is a process by which organization evaluate employee job performance (Werther \& Davis, 1985). Typical Outcomes from annual appraisals are misdirected bonuses, too painful, emotionally charged, poor understanding of expectations, bad timing, subjective manager opinion, performance not aligned to promotions, poor development opportunities and no consequence for non-participation.

Mediating variable of this research is job satisfaction. The level of job satisfaction is affected by intrinsic and extrinsic motivating factors, the quality of supervision, social relationships with the work group and the degree to which individuals succeed or fail in their work. Purcell et al (2003) believe that discretionary behavior which helps the firm to be successful is most likely to happen when employees are well motivated and feel committed to the organization and when the job gives them high levels of satisfaction. Their research found that the key factors affecting job satisfaction were career opportunities, job influence, teamwork and job challenge.

As indicated indirectly in a study of HR professionals (Rynes, et al., 2002), as well as based on our experience, the major practitioner knowledge gaps in this area are:

i. The causes of employee attitudes

ii. The results of positive or negative job satisfaction

iii. How to measure and influence employee attitudes 
Job satisfaction is how content an individual is with his or her job. The term 'job satisfaction' refers to the attitudes and feelings people have about their work. Positive and favorable attitudes towards the job indicate job satisfaction. Negative and unfavorable attitudes towards the job indicate job dissatisfaction.

Limited resources can be a barrier to implement a good work life policy. Other than this a lack of awareness about flexible work options and leave entitlement, inability to access flexible work arrangements, lack of understanding of the benefits and lack of effective communications between the management and employers are some of the barriers to an effective work life balance implementation process. Some of the managers believe that work life policies can reduce the productivity of the organization by giving more freedom to the employers.

As reported in the Daily Mirror (October 9th, 2010), "25\% of Sri Lankans are mentally ill". The National council for mental health (NCMH) further explains that one in four Sri Lankans suffers from various kinds of mental illnesses in the recent years. NCMH Director Mendis told the causes of mental illnesses are stress, alcohol, drugs, smoking, diabetes and an unhealthy lifestyle. According to research, the number of stress related disability claims has doubled in recent years. Workers in high stress jobs are three times as others to suffer stress related medical conditions, including cardiovascular disease, frequent headaches and weakened immune system. Stress can also lead to inappropriate coping mechanisms, such as the abuse of alcohol, smoking and drug abuse.

\section{Theoretical Framework}

This is an explanatory model and specifies the nature of hypotheses of the study, which were set out in diagrammatic form of figure 01. According to the model, independent variable is "Work Life Balance", dependent variable is "Employee Performance" and mediating variable is "Employee Job Satisfaction". They can be described as follows. 


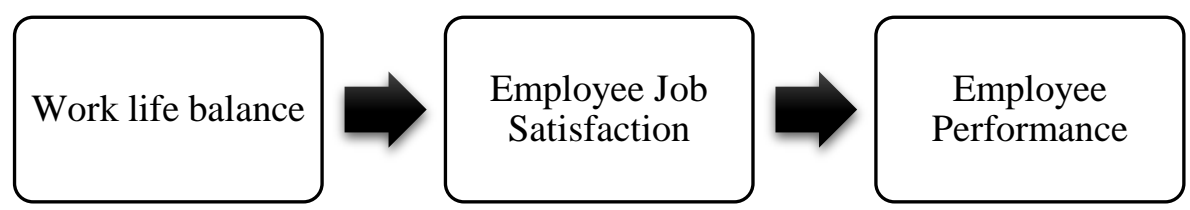

Figure 01: Conceptual Framework of the Study

Source: Authors (2017)

\section{Conceptualization of Independent Variable (Work Life Balance)}

\subsection{Working Definition}

"Work Life Balance isn't only about families and childcare. Nor is it about working less. It's about working smart. About being fresh enough to give all you need to both work and home, without jeopardising one for the other. And it's a necessity for everyone, at whatever your stage in life."

The good practice of work life balance leads both employees and the organization to get benefits. Basically, employees benefit by feeling less stressed and happier both at work and at home. And more people have the opportunity for paid work. A business benefit from having more motivated, more productive and less stressed work force and staff are more likely to stay with their employer. This reduces the cost of recruitment as well as retaining skills and experiences. Both customers and the clients benefit from a consistent service.

The achievement of better WLB can yield dividends for employers in terms of having a more motivated, productive, less stressed workforce, increased productivity, and reduced absenteeism. WLB can have impact on both individual as well as the organization. Dimensions for measuring work life balance are work centered life and family centered life. Indicators for measuring work life balance are work hours, work load, supervisors, subordinates, peers (work centered life) spouse, children, relatives and elder care (family centered life). 


\section{Conceptualization of Dependent Variable (Employee Performance)}

\subsection{Working Definition}

"Employee performance means the ability of an employee to perform the job in a particular way that is leads to both organization and the employee to achieve their common goals and objectives."

Performance means the end results of an activity of a person or an organization. Further, organizational performance can be described as the accumulated end result of all the organization's work process and activities. Like all ratios it can be improved by increasing the output, decreasing the input or both.

Employee performance management is a process for establishing a shared workforce understanding about what is to be achieved at an organization level. It is about aligning the organizational objectives with the employees' agreed measures, skills, competency requirements, development plans and the delivery of results. The emphasis is on improvement, learning and development in order to achieve the overall business strategy and to create a high performance.

Performance evaluation is a systematic process by which the organization determines the degree to which the employee is performing the job in relation to the set norms and standards for a particular period of time and identifies the employee potential for development workforce.

Dimensions for measuring employee performance is quantitative dimension and qualitative dimension. Indicators for measuring employee performance are work targets, project deadlines, limited resources (quantity) new ideas, errors at work and time utilization (quality).

\section{Conceptualization of Mediating Variable (Employee Job Satisfaction)}

\subsection{Working Definition}

"Job satisfaction is how content an individual is with his or her job. The term 'job satisfaction' refers to the attitudes and feelings people have about their 
work. Positive and favorable attitudes towards the job indicate job satisfaction".

The level of job satisfaction is affected by intrinsic and extrinsic motivating factors, the quality of supervision, social relationships with the work group and the degree to which individuals succeed or fail in their work. Employees have attitudes or viewpoints about many aspects of their jobs, their careers, and their organizations. However, from the perspective of research and practice, the most focal employee attitude is job satisfaction. Negative and unfavorable attitudes towards the job indicate job dissatisfaction. Morale is often defined as being equivalent to job satisfaction. Morale is 'the extent to which an individual's needs are satisfied and the extent to which the individual perceives that satisfaction as stemming from his (sic) total work situation'.

Dimensions for measuring employee job satisfaction are corporate culture and rewards. Indicators for measuring employee job satisfaction are work style, communication (corporate culture) wages/salaries, incentives and welfare facilities (rewards).

\section{Hypotheses}

Based on the conceptual model the following hypotheses were developed for testing.

H1: There is a positive relationship between work life balance and employee performance.

H2: There is a positive relationship between work life balance and employee job satisfaction.

H3: There is a positive relationship between employee job satisfaction and employee performance.

H4: Work life balance positively leads to higher level of employee performance through employee job satisfaction. 


\section{Methodology}

The methodology used in this research is deductive approach. The purpose of this study is explanatory. Studies that engage in hypotheses testing usually explain the nature of certain relationship, or establish the difference among group or the independence of two or more factors in a situation (Sekaran, 2009). Researcher has tested the nature of the certain impact among main two variables. That means this research emphasized there is a significant impact of work life balance on employee performance in telecommunication industry in Sri Lanka. The researcher should determine whether a causal or a correlation relational study is needed to find an answer to the issue at hand (Sekaran, 2009).

The study in which the researcher wants to delineate the cause of one or more problems is called a causal study. When the researcher is interested in delineating the important variables associated with the problem, the study is called a correlational study (Sekaran, 2009). Accordance with above point, in this research problem a correlational study was need. The extent of interference by the researcher with the normal flow of work at the workplace has a direct bearing on whether the study undertaken is causal or correlational (Sekaran, 2009).

A correlational study is conducted in the natural environment of the organization with minimum interference by the researcher with the normal flow of work (Sekaran, 2009). In this study, researcher examined the impact of work life balance on performance level of employees through the executive level married employees in Dialog Axiata PLC and Sri Lanka Telecom. Further, this can be identified as a correlational study. In this case, data was collected through distributing questionnaire to employees who work in Dialog Axiata PLC and Sri Lanka Telecom. Researcher had not affected with the normal activities in both companies. Hence, researcher interference had been minimal. Organizational research can be done in the natural environment where work proceeds normally (that is, in non-contrived settings) or in artificial, contrived settings (Sekaran, 2009). Correlational studies are invariably conducted in no contrived settings, whereas most rigorous causal studies are done in contrived lab settings (Sekaran, 2009). Correlational studies done in organizations are called field studies (Sekaran, 2009). This research is a field study; researcher here was done in a no 
contrived setting with no interference with the normal work routine. The unit of analysis refers to the level of aggregation of the data collected during the subsequent data analysis stage (Sekaran, 2009). In this research, the problem statement focused on how work life balance impact on performance level of employees, and then researcher was interested in executive level married employees in Dialog Axiata PLC and Sri Lanka Telecom. Here the unit of analysis is individual employees.

A study can be done in which data are gathered just once, perhaps over a period of days or weeks or months, in order to answer a research question. Such studies are called one shot or cross- sectional studies (Sekaran, 2009). The researcher might want to study people or phenomena at more than one point in time in order to answer the research question, are called longitudinal studies (Sekaran, 2009). In This study data were gathered just once, perhaps over a period of days, in order to answer a research question. Therefore, this study can be identified as cross- sectional study.

The target population of this research is executive level married employees in telecommunication industry in Sri Lanka. Mobitel (Pvt)Ltd, Dialog Axiata plc, HUTCH , Lanka Bell Limited, Sri Lanka Telecom, Airtel, Tritel and Etisalat. The research sample has been selected from executive level married employees in telecommunication industry in Sri Lanka. This investigation area is used Cluster sampling method to select 2 major companies in telecommunication industry. Sample is Dialog Axiata PLC and Sri Lanka Telecom. Sample size is 100 .

Primary data is collected thorough structured questionnaire. The questionnaire included pre -coded, single choice questions. The questioner has 2 sections. In Section A, the researcher has included the personal profile of the selected employees. In this section, the researcher included the age, experience of employees, gender, number of children of employees and mode of transport of selected employees. In Section B, 1-36 questions have been included to measure quality of work life balance, employee performance and employee job satisfaction. Statements were given to measure the impact of work life balance on employee performance with five point Likert scales ranging from strong agree to strong disagree. 
Secondary data collection for the following research was gathered by the help of previous researcher's articles, journals, research reports, company manuals, related text books and internet. The current researcher used measures of central tendency (mean, median and mode), measures of dispersion (standard deviation), and measures of skewness, the regression analysis and coefficient of correlation analysis to find the relationship between variables for test the hypothesis.

\section{Reliability and Validity}

To test the internal consistency of the instrument Cronbach's Alpha was used. The results of Cronbach's Alpha are shown in following table.

Table 1: Reliability Statistics

\begin{tabular}{|l|l|l|}
\hline \multicolumn{1}{|c|}{ Variables } & \multicolumn{1}{|c|}{ Cronbach's Alpha } & No. of Items \\
\hline Work Life Balance & 0.849 & 19 \\
\hline Employee Performance & 0.694 & 11 \\
\hline Employee Job Satisfaction & 0.956 & 7 \\
\hline
\end{tabular}

Work Life Balance is an independent variable of this research and 19 questions of work life balance reliability is 0.849 (80\%).Dependent variable of this research is employee performance and 11 questions of employees performance reliability is 0.694 (70\%). Employee job satisfaction is mediating variable of this research and reliability is $0.956(100 \%)$ for 07 questions of employees job satisfaction. It is positive reliability of research. Therefore, as per the data, overall reliability of study is acquired.

\section{Data Analysis}

Univariate, bivariate and multivariate analyses were done in order to achieve the set objectives and to test hypotheses of the study. Pearson correlation and regression were used to test hypotheses and descriptive statistics were used to do univariate analysis. 


\section{Univariate Analysis}

The gender difference of the tested sample from executive level married employees in Dialog Axiata PLC and Sri Lanka Telecom. According those details, the researcher can observe that males are $26 \%$ of the sample and Females are $74 \%$ of the sample. The percentage of the female employees of Dialog Axiata PLC and Sri Lanka Telecom is greater than the male employees. Age groups of employees in the sample have been grouped into three categories. The highest representation of the employees was included to the 31-40 age groups in the sample. From sample of 100 executive level married employees 2 employees don't have children while 27 employees have 1 child. 31\% of sample has 2 children and also same percentage is for employees who have 3 children. Only 9\% employees have more than 3 children. Further, time period in present job of employees in the sample have been grouped into five categories. The highest representation of the employees was included to the 04-06 years groups in the sample.

Education levels of employees in the sample have been grouped into four categories such as Advanced level, Diploma, Graduate and MBA. The first category Advanced level 22 employees and it is $22 \%$ of the sample. Diploma contains 24 employees and it is $24 \%$ of the sample. Third one is Graduate and it contains 34 employees and it is $34 \%$ of the sample which is the highest percentage among all four categories. There are 20 employees at the category of MBA it is $20 \%$ of the sample. Way of coming to work pattern is little bit differ. A few $10 \%$ is walking to their work place. Both group of office transport users and personal transport users are around $33 \%$. $23 \%$ of people are coming by bus. 
Table 02: Statistics of the Distribution of WLB of the Sample

\begin{tabular}{|l|c|}
\hline Mean & 4.0200 \\
\hline Median & 4.0000 \\
\hline Mode & 4.00 \\
\hline Std. Deviation & .60269 \\
\hline Skewness & -.855 \\
\hline Kurtosis & 2.875 \\
\hline
\end{tabular}

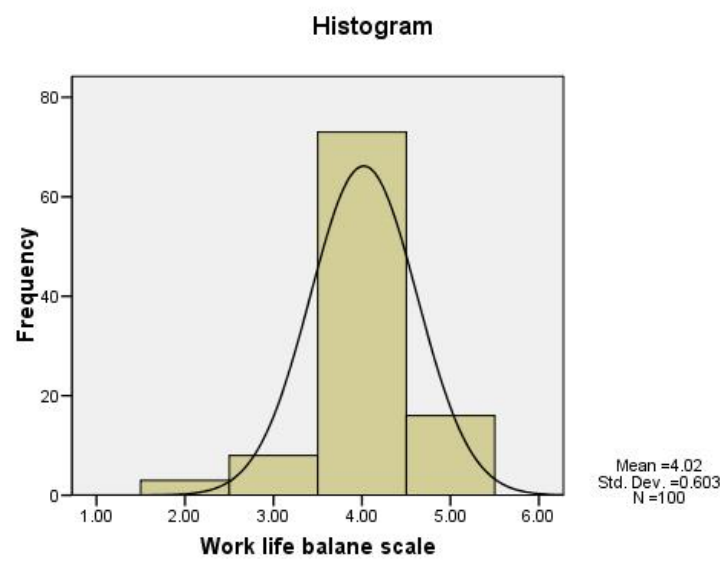

Figure 02: Histogram of WLB

Source: Survey Data

The frequency distribution analysis was made individually for the independent variable of work life balance. The frequency distribution of work life balance is presented in the table 1 . As indicated by the table 1 the mean value of the distribution is 4.0200. It means that work life balance of respondents is "High". Both mode and median values are 4.The skewness and kurtosis of the distribution are -0.855 and 2.875which indicated that the data recorded for the WLB are approximately normally distributed. The Std. Deviation is 0.60269 which indicates that mean value is confirmed as a great value and it shows all figures are near to mean and mean value is suitable as a value to represent all data. 
Table 03: Statistics of the Distribution of EP of the Sample

\begin{tabular}{|l|c|}
\hline Mean & 3.8100 \\
\hline Median & 4.0000 \\
\hline Mode & 4.00 \\
\hline Std. Deviation & .59789 \\
\hline Skewness & -.778 \\
\hline Kurtosis & 1.521 \\
\hline
\end{tabular}

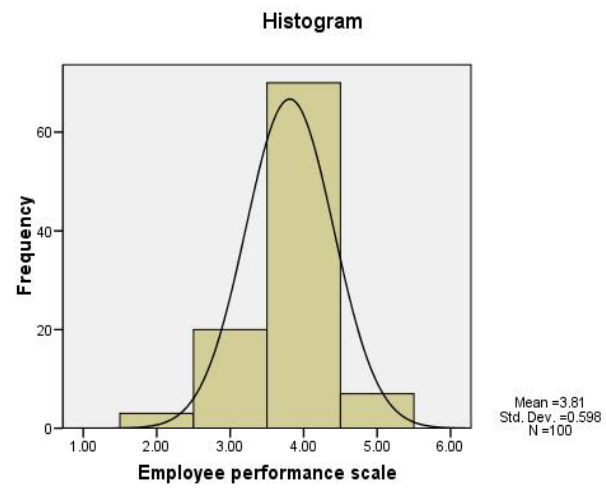

Figure 3: Histogram of EP

Source: Survey Data

The frequency distribution analysis was made individually for the dependent variable of employee performance. The frequency distribution of EP is presented in the table 3.As indicated by the table 3 the mean value of the distribution is 3.8100. That means employee performance of respondents is "High". Both median and mean values are 4. The skewness and kurtosis of the distribution are -0.778 and 1.521 which indicated that the data recorded for the EP are approximately normally distributed. The Std. Deviation is 0.59789 which indicates that mean value is confirmed as a great value and it shows all figures are near to mean and mean value is suitable as a value to represent all data.

Table 04: Statistics of the Distribution of EJS of the Sample

\begin{tabular}{|l|l|}
\hline Mean & 4.4100 \\
\hline Median & 5.0000 \\
\hline Mode & 5.00 \\
\hline Std. Deviation & .99590 \\
\hline Skewness & -1.468 \\
\hline Kurtosis & .745 \\
\hline
\end{tabular}




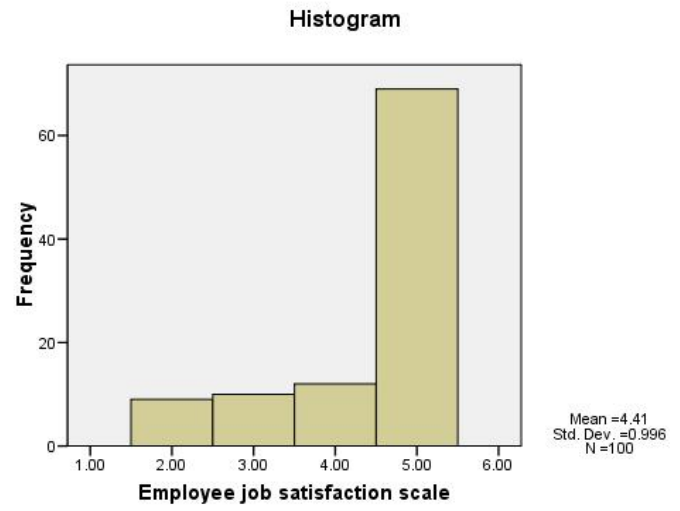

Figure 4: Histogram of EJS

\section{Source: Survey Data}

The frequency distribution analysis was made individually for the mediating variable of employee job satisfaction. The frequency distribution of EJS is presented in the table 4 . As indicated by the table 4 the mean value of the distribution is 4.4100. That means employee job satisfaction of respondents is "High". Both median and mode values are 5.That is there are highly satisfied employees. The skewness and kurtosis of the distribution are -1.468 and .745 which indicated that the data recorded for the EJS are negatively skewed. The Std. Deviation is 0.99590 which indicates that mean value is confirmed as a great value and it shows all figures are near to mean and mean value is suitable as a value to represent all data.

\section{Bivariate Analysis}

This is descriptive statistics for the strength of relationship between two variables. The Bivariate analysis includes the correlation analysis and simple regression. Using the Pearson Product Movement Correlation with one-tailed test of significance, the Correlation analysis was made to investigate any relationships. 
Table 05: Correlation Matrix of the Variables

\begin{tabular}{|c|c|c|c|c|c|}
\hline Variable & 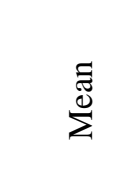 & 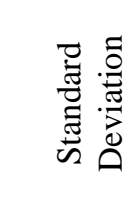 & $\frac{\infty}{3}$ & 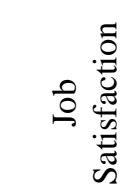 & 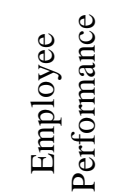 \\
\hline WLB & 4.0200 & 0.60269 & 1 & & \\
\hline Job Satisfaction & 4.4100 & 0.577 & $0.575^{* *}$ & 1 & \\
\hline Employee Performance & 3.8100 & 0.99590 & $0.543^{* *}$ & $0.522 * *$ & 1 \\
\hline
\end{tabular}

** Correlation is significant at the 0.01 level (1-tailed).

According to the results of the Pearson's correlation shown in the table 5, there is a positive significance between work life balance and employees performance. Pearson correlation between the two variables is .543, which is positive. It shows that there is a relationship between work life balance and employee performance and the existing relationship is positive. Since correlation value is more than +0.5 and nearest to the +1 , that relationship is much strong. Further, the relationship is statistically significant as correlation is significant at 0.01 levels (1-tailed). Thus, there is a statistical evidence to prove that work life balance and employee performance are related. As well as that relationship is positive and very strong.

According to the results of the Pearson's correlation shown in the table 5, there is a positive significance between Work life balance and Employee job satisfaction. Pearson correlation between the two variables is .575, which is positive. It shows that there is a relationship between work life balance and employees job satisfaction and the existing relationship is positive. Since correlation value is more than +0.5 and nearest to the +1 , that relationship is much strong. Further, the relationship is statistically significant as correlation is significant at 0.01 levels (1-tailed). Thus, there is a statistical evidence to prove that work life balance and employees job satisfaction are related. As well as that relationship is positive and has very strong relationship. Further, as per the table 5 , there is a positive significance relationship between employee job satisfaction and employee performance. Pearson correlation between the two variables is .522, which is positive. It shows that there is a 
relationship between employee's job satisfaction and employee performance and the existing relationship is positive. Since correlation value is more than +0.5 and nearest to the +1 , that relationship is much strong. Moreover, the found relationship is statistically significant as correlation is significant at 0.01 levels (1-tailed). Thus, there is a statistical evidence to prove that employees job satisfaction and employee performance are related. As well as that relationship is positive and has very strong relationship.

\section{Testing Mediation Effect}

Simple regression and multiple regression results were used to identify the mediation effect. From table 6 and 7 represent the regression analyses.

Table 06: Simple Regression Analysis for WLB and EP

\begin{tabular}{|c|c|c|c|c|c|c|c|}
\hline $\begin{array}{l}\frac{0}{0} \\
. \frac{\pi}{\Xi} \\
>\end{array}$ & 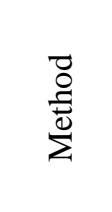 & 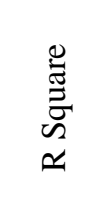 & 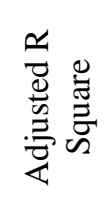 & I工 & $\stackrel{00}{\infty}$ & 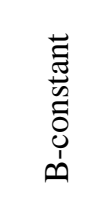 & 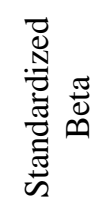 \\
\hline WLB & Linear & 0.295 & 0.288 & 41.032 & 0.000 & 1.643 & 0.543 \\
\hline
\end{tabular}

Source: Survey Data

The result of regression of independent variable is work life balance against the dependent variable (Employees Performance) are shown in the table. According to the table 05 , the $b$ value of the equation, the gradient of the regression, is 0.543 , which is significant at $1 \%$ (significant $=0.000$ ). As indicated by adjusted $\mathrm{R}$ squared, only $28.8 \%$ of the variance of Employee Performance is explained by Work Life Balance with the standardized beta of 0.543 . That means balance $71.2 \%$ is explained by other factors. The F value is 41.032 , which is significant at $1 \%(\mathrm{P}=0.000)$, which suggests that work life balance has significantly explained $28.8 \%$ of the variance of Employee Performance.

$$
E P=1.643+0.543 W L B
$$

In here the WLB value is (+0.543). Hence, there is a positive relationship between WLB and EP. That means if the WLB increased relatively that the 
employee performance also increased. Above the equation the WLB increased by 1 unit, the EP also increased by (+0.543). And also the intercept value is +1.643 . That means the employee performance is 1.643 when there is no work life balance exists.

Table 07: Simple Regression analysis for WLB and EJS

\begin{tabular}{|c|c|c|c|c|c|c|c|}
\hline 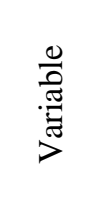 & 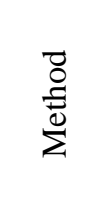 & 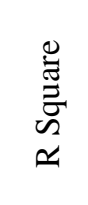 & 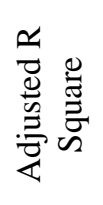 & I & 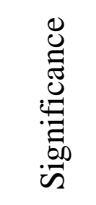 & 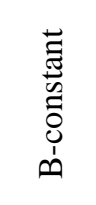 & 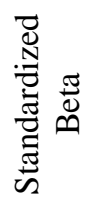 \\
\hline WLB & Linear & 0.331 & 0.324 & 48.459 & 0.000 & 0.589 & 0.575 \\
\hline
\end{tabular}

Source: Survey Data

According to the table 07, the b value of the equation, the gradient of the regression, is 0.575 , which is significant at $1 \%$ (significant $=0.000$ ). As indicated by adjusted R squared, only $32.4 \%$ of the variance of Employee Job Satisfaction is explained by Work Life Balance with the standardized beta of 0.575 . That means balance $67.6 \%$ is explained by other factors. The $\mathrm{F}$ value is 48.459 , which is significant at $1 \%(\mathrm{P}=0.000)$, which suggests that work life balance has significantly explained 32.4\% of the variance of Employee Job Satisfaction.

$$
\mathrm{JS}=0.589+0575 \mathrm{WLB}
$$

In here the WLB value is (+0.575). So there is a positive relationship between WLB and EJS. That means if the WLB increased relatively that the employee job satisfaction also increased. Above the equation the WLB increased by 1 unit, the EJS also increased by $(+0.575)$. And also the intercept value is +0.589 . It means that the employee job satisfaction is 0.589 when there is no work life balance exists. 
Table 08: Simple Regression Analysis for EJS and EP

\begin{tabular}{|c|c|c|c|c|c|c|c|}
\hline 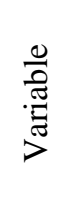 & 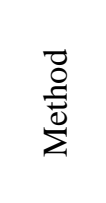 & 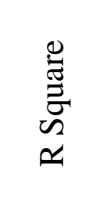 & 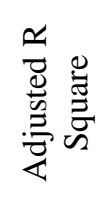 & {$[I$} & 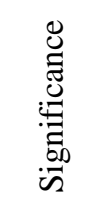 & 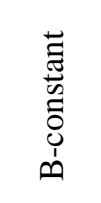 & 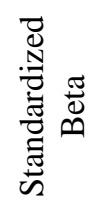 \\
\hline EJS & Linear & 0.273 & 0.265 & 36.767 & 0.000 & 2.427 & 0.522 \\
\hline
\end{tabular}

Source: Survey Data

According to the table 08 , the $\mathrm{b}$ value of the equation, the gradient of the regression, is 0.522 , which is significant at $1 \%$ (significant $=0.000$ ). As indicated by adjusted R squared, only 26.5\% of the variance of Employee Performance is explained by Employee job satisfaction with the standardized beta of 0.522 . It means that balance $73.5 \%$ is explained by other factors. The F value is 36.767 , which is significant at $1 \%(\mathrm{P}=0.000)$, which suggests that employee job satisfaction has significantly explained $26.5 \%$ of the variance of Employee Performance.

According to the results of Pearson's Product Movement correlation analysis between WLB and EP, the correlation coefficient is 0.543 , which is significant at $1 \%(\mathrm{p}=0.000)$. As per the result of simple regression analysis between the two variables the regression coefficient (b) is 0.543 which is significant at $1 \%(\mathrm{~T}=0.000)$. Therefore according to the results of both tests, the Null Hypothesis is rejected and the Alternative Hypothesis is accepted since $r>0$, and $b>0$, consequently, relationship is positive. Hence data support the hypothesis that there is a positive relationship between WLB and EP in telecommunication industry in Sri Lanka.

According to the results of Pearson's Product Movement correlation analysis between WLB and EJS, the correlation coefficient is 0.575, which is significant at $1 \%(\mathrm{p}=0.000)$. As per the result of simple regression analysis between the two variables the regression coefficient (b) is 0.575 which is significant at $1 \%(\mathrm{~T}=0.000)$. Therefore according to the results of both tests, the Null Hypothesis is rejected and the Alternative Hypothesis is accepted since $r>0$, and $b>0$, consequently, relationship is positive. Hence data support the hypothesis that there is a positive relationship between WLB and EJS in telecommunication industry in Sri Lanka. 
According to the results of Pearson's Product Movement correlation analysis between EJS and EP, the correlation coefficient is 0.522 , which is significant at $1 \%(\mathrm{p}=0.000)$. As per the result of simple regression analysis between the two variables the regression coefficient (b) is 0.522 which is significant at $1 \%$ $(\mathrm{T}=0.000)$. Therefore according to the results of both tests, the Null Hypothesis is rejected and the Alternative Hypothesis is accepted since $r>0$, and $b>0$, consequently, relationship is positive. Hence data support the hypothesis that there is a positive relationship between EJS and EP in telecommunication industry in Sri Lanka.

Table 09: Multiple Regression of WLB and EJS on EP

\begin{tabular}{|c|c|c|c|c|}
\hline R Square & $\begin{array}{c}\text { Adjusted R } \\
\text { Square }\end{array}$ & $\begin{array}{c}\text { Std. Error of the } \\
\text { Estimate }\end{array}$ & F & Significance \\
\hline .361 & .348 & .48287 & 27.391 & 0.000 \\
\hline
\end{tabular}

Source: Survey Data

The Adjusted R Square is 0.348 , which indicates that $34.8 \%$ of the variation in Employee Performance is explained by the two independent variables jointly. The F Value is 27.391 which is significant at $1 \%(\mathrm{p}=0.000)$, which suggest that the both independent variables have significantly explained 34.8 $\%$ of the variation in the Employee Performance.

A mediation model is one that seeks to identify and explicate the mechanism or process that underlies an observed relationship between an independent variable and a dependent variable via the inclusion of a third explanatory variable, known as a mediator variable. Rather than hypothesizing a direct causal relationship between the independent variable and the dependent variable, a mediational model hypothesizes that the independent variable influences the mediator variable, which in turn influences the dependent variable. Thus, the mediator variable serves to clarify the nature of the relationship between the independent and dependent variables.[1] In other words, mediating relationships occur when a third variable plays an important role in governing the relationship between the other two variables.

As a multivariate analysis, the multiple regression analysis was used to identify the mediation effect. Multiple regressions results indicate that there 
is mediation effect among variables and the value of mediation effect is $18 \%$. That means work life balance positively leads to higher level of employee performance through employee job satisfaction. It means there is $18 \%$ of moderate effect from employee job satisfaction to relationship between work life balance and employee performance.

\section{Discussions and Conclusion}

It was found that there is a positive relationship between WLB and EP. The correlation between these variable was 0.543 , which is significant at 0.000 levels. This was based on one- tailed tests. Since correlation value is more than +0.5 and nearest to the +1 , that relationship is much strong.

The simple regression analysis describes that WLB has a positive impact on $E P$ with the strength of $b$ value of $0.543(F=41.032, P=0.000)$. The level of WLB gives a measure of EP and it has a $28.8 \%$ accuracy of predicting. That is $28.8 \%$ of EP is accounted for by WLB.

Discussing the level of WLB of telecommunication industry in the sample, it was found that they have a high level of WLB with the mean value of 4.02 and standard deviation of 0.60269 . Accordingly it was found that WLB in telecommunication Industry were good.

Several studies have examined the relationship between work life balance and employee performance with mixed results. According to DTI Scotland office (2000), the good practice of work life balance leads both employees and the organization to get the benefits. Basically, employees benefit by feeling less stressed and happier both at work and at home. And more people have the opportunity for paid work. Ultimately, these things cause to increase employee performance.

It was found that there is a positive relationship between WLB and EJS. The correlation between these variables was, 0.575 which is significant at 0.000 levels. This was based on one- tailed tests. Since correlation value is more than +0.5 and nearest to the +1 , that relationship is much strong.

The simple regression analysis describes that WLB have a positive impact on $E P$ with the strength of $b$ value of $0.575(F=48.459, P=0.000)$. The level of WLB give a measure of EJS and it has a $32.4 \%$ accuracy of predicting. That is $32.4 \%$ of EJS is accounted for by WLB. 
Discussing the level of EJS of telecommunication industry in the sample, it was found that they have a High level of EJS with the mean value of 4.41 and standard deviation of .99590. Accordingly it was found that EJS in telecommunication Industry were good.

It was found that there is a positive relationship between EJS and EP. The correlation between these variable was, 0.522 which is significant at 0.000 levels. This was based on one- tailed tests. Since correlation value is more than +0.5 and nearest to the +1 , that relationship is much strong. The simple regression analysis describes that EJS has a positive impact on EP with the strength of $b$ value of $0.522(\mathrm{~F}=36.767, \mathrm{P}=0.000)$. The level of EJS gives a measure of EP and it has a $26.5 \%$ accuracy of predicting. That is $26.5 \%$ of EP is accounted for by EJS.

Discussing the level of EP of telecommunication industry in the sample, it was found that they have a High level of EP with the mean value of 3.81and standard deviation of .59789. Accordingly it was found that EP in telecommunication Industry was good.

The study of the relationship between job satisfaction and job performance has a controversial history. The Hawthorne studies, conducted in the 1930s, are often credited with making researchers aware of the effects of employee attitudes on performance. Shortly after the Hawthorne studies, researchers began taking a critical look at the notion that a "happy worker is a productive worker". Most of the earlier reviews of the literature suggested a weak and somewhat inconsistent relationship between job satisfaction and performance. A review of the literature in 1985 suggested that the statistical correlation between job satisfaction and performance was about .17 (Iaffaldano \& Muchinsky, 1985). Thus, these authors concluded that the presumed relationship between job satisfaction and performance was a "management fad" and "illusory." This study had an important impact on researchers, and in some cases on organizations, with some managers and HR practitioners concluding that the relationship between job satisfaction and performance was trivial. However, further research does not agree with this conclusion.

According to multiple regressions, effect indicates that there is mediation effect among variables and the value of mediation effect is $18 \%$. It means that 
work life balance positively leads to higher level of employee performance through employee job satisfaction. It means that there is $18 \%$ of moderate effect from employee job satisfaction to relationship between work life balance and employee performance. Hence, it is concluded that the better WLB of the employees leads to increased employee performance and employee job satisfaction.

Based on the empirical investigation of the research the researcher can conclude that there is a strong relationship between work life balance and employee performance, a strong relationship between work life balance and employee job satisfaction and a strong relationship between employee job satisfaction and employee performance. All these relationships are positive and have significant levels. In conclusion the author would like to emphasize that; to improve WLB in an organization, support from both management and employees is very important.

\section{Recommendations}

Based on the findings discussed in above, recommendations would be given for the employees and the management of the organization to improve WLB in order to enhance the employee performance and the employee job satisfaction of the organization. The recommendations will be in relation to WLB practices identified through the literature review and the feedback of the questionnaires.

\section{$>$ Training Programmes}

The author has recommended for the management to conduct training programmes in relation to WLB, through which organization can improve the WLB of their staff. Given below are some of the training programmes suggested by the author in order to enhance the WLB of the employees.

- Time management and personal effectiveness - This training programme can be based on individual and organization needs which includes work life balance theme. Work life balance issues can be also included in these types of training programmes.

- Effective work load management - This training programme can include assessing current WLB and how it affects the employee, 
explain the causes of imbalance, and strategies for upgrading the quality of employees' lives and train the employees to create the life and work goals.

- Personal and professional development training courses - This is to encourage the balance between work and life to enable individuals, organizations, and families to be the very best that they can be in all their areas of endeavor.

- Life management training courses - This type of training programmes helps the employees to recognize the issues and challenges and allow them to make significant lifestyle changes. It enhances employee's ability to focus on the job in priority wise.

Further, the training plan would also focus upon the managers as well. Training programmes for managers should be conducted on topics such as dealing with problems, motivate the employees, effective communication with subordinates, and training courses on leadership and management which would ensure the improvement in WLB of the employees in order to enhance the overall WLB of the organization.

\section{$>$ Stress Management}

Stress management services and programmes should be provided by an external company specializing in this type of support, information and counseling service. These services should be confidential and can be offered to either individuals or groups of employees. The benefits of this programme can include decreased absenteeism, accidents and stress related disability. It can lead to increased employee productivity and prevention of problems, which could negatively impact the employee's work and home life.

\section{$>$ Flex-work Arrangements}

Flextime is an arrangement whereby employees can vary the scheduling of their working hours within specified guidelines. Essentially, it allows employees, on an individual or collective basis, to determine the start and end times of their working day. Flextime allows the employees to plan their workday around their personal lives. This practice can reduce the tardiness 
and absenteeism, increases in employee morale and employee job satisfaction and ultimately employee performance.

\section{$>$ Tele Working}

Tele work, also referred to as telecommuting, is an arrangement whereby an employee, at least on a periodic basis, fulfills his or her regularly scheduled job responsibilities at a remote place. (Own residence) Tele work can advantage for employees as they can organize their workday around their personal and family needs. It can also decrease the transport expenses and reduce commuting time. Tele work allows to work in a less stressful and disruptive environment.

\section{$>$ Workplace Child Care}

Employees may have their children looked after at or near the workplace. The child care center may be owned by the company or be managed by a board of directors that includes representatives of the company and parents whose children go to the center. This facilitates the employees to easier access to a child care service and help to reduce the stress experienced by the parents.

\section{$>$ Health and Safety Promotion}

A healthy workplace provides mutual benefits for employers and employees within a common belief that good health practices by both will lead to individual and organizational self-fulfillment and productivity. Health promotion is the process of enabling employees to increase control over and to improve their physical, emotional and social health. This programme enables all the employees to improve health and maintain their good health. Therefore, the types of health activities can have positive impact on physical, emotional, and social environment.

\section{Limitations of the Study}

The main limitation of the study is, the research is limited to executive level married employees in telecommunication industry in Sri Lanka. Further, this research is based on response to questionnaires; employees' perception about this research will decide the successful of this research. Further, time is not enough to find data and information and the scope of the study is limited to 
the geographical boundaries of, Sri Lanka, where the population is telecommunication industry. Another limitation is that there may be some bias information of employees due to their fear and doubt about the supervisor's response towards their employees' answers, and job security.

\section{References}

Andrew Oswald, (2002). Are You Happy at Work? Job Satisfaction and Work-Life Balance in the US and Europe, http://www.mendeley.com.

Bloom, N., Kretschmer, T., \& Reenen, V., (2006). Work Life BalanceManagement Practices and Productivity. [Online] Centre for Economic Performance. Available from: http://cep.lse.ac.uk.

Department of Trade and Industry, (2001). The Essential Guide to - Work-life Balance. London: DTI. Available from: http://www.flexibleworking.co.uk.

Doble, N., \& Supriya, M.V., (2010). Gender differences in the perception of work life balance. From:http://www.fm-kp.si/zalozba.

Dimensions of Corporate Culture December 28, 2007 by Steve Rosenbaum. From: http://learningatlightspeed.wordpress.com.

Explain what is Employee Performance Management? From www.peoplestreme.com.

Families and Work Institute's 1997 National Study of the Changing Workforce. (Bond et al., 1998)

Fursman, L., (2003). Work life balance in New Zealand: <http://pdfcast.org.

Greenhaus, J. H., \& Beutell, N. J. (1985). Sources of conflict between work and family roles. Academy of Management Review, 10, 76-88.

Guest, D.E., (2001). Perspectives on the study of work life balance. $<$ http://www.ucm.es/info.

Guest, D.E., (2001). Perspectives on the study of work life balance. $<$ http://www.ucm.es/info. 
Hogarth, T., Catheirne, B., \& Daniel, G., (2000). Work life balance -2000: Results from the Baseline study. Department for Education and Employment.<http://www.education.gov.uk/research.

Human Resources Management International Digest, (2004). Leeds lists the benefits of better work life balance: Councils reap the rewards of family friendly policies volume: 12 .

Johnson, T.W., \& Stinson, J.E. (1975), “'Role ambiguity, role conflict, and satisfaction: mediating effects of individual differences", Journal of Applied Psychology, Vol. 60 No. 3, pp. 329-33.

Lyons, T.F. (1971), "'Role clarity, need for clarity, satisfaction, tension and withdrawal", Organisational Behaviour and Human Performance, Vol. 6, pp. 99-110

Maxwell, A. (2004). Checks and balances: the role of managers in work-life balance policies and practices < doi:10.1016/j.jretconser.2004.06.002>

Melissa, A. (2007). A Report on the Importance of Work-life Balance http://www.bia.ca/articles.

Mulvaney, R.H, John, W., \& Jeanette, N., (2006). A framework for work-life balance practices. $<\mathrm{http}: / / \mathrm{www}$.sciencedirect.com/science.

Ohio LINK EJC - Development and initial validation of a measure of supportive and unsupportive managerial behaviors $<$ http://journals.ohiolink.edu.

PsycINFO Database Record (c) 2010

Research Methods for Business by Uma Sekaran 2009.

Taylor, R., (2002). Britain's World of Work and Realities. Future of Work Programme.15 (4), 9-16. Available from: Economic and Social Research Council. <www.esrc.ac.uk >

Telecommunication Regulatory Commission of Sri Lanka from: http://www.trc.gov.lk.

The difference between performance management and performance appraisal http://www.hotelmule.com/forum/viewthread.php?tid=393 
Kelaniya Journal of Human Resource Management

Volume 12, Number 01 - January 2017

What is Employee Performance Management? From:

http://www.peoplestreme.com.

Work Performance - Workplace Health and Safety Queensland from:

http://www.deir.qld.gov.au.

Yeandle, S., Wigfield, A., Crampton, R., \& Dennett, J., (2002). Employed careers and family-friendly employment policies [online] London: The policy press. Available from: http://www.jrf.org.uk. 